\section{Neurología paso a paso}

Comentario sobre el texto "Neurología paso a paso" de Humberto Oscar Chade. Editorial de la Universidad del Aconcagua, Mendoza 2008, 424 páginas.

$\mathrm{E}$ 1 texto "Neurología paso a paso" recién publicado por el Profesor Titular de Neurología de la Universidad del Aconcagua (Mendoza; Argentina) Humberto Oscar Chade es un aporte importante a la formación médica de habla hispana. Su gran experiencia clínica y docente le permiten revisar ordenadamente la compleja patología del sistema nervioso.

Esta revisión se inicia con capítulos generales sobre estructura, función y patología del sistema nervioso, capítulos que serán especialmente útiles para el estudiante de pregrado y el médico no especialista. Además termina con consideracio- nes actualmente indispensables, sobre rehabilitación y problemas éticos en Neurología.

En cada uno de los temas tratados se expresan, por una parte, la erudición; y por otra, la capacidad de limitar la entrega a lo que realmente es necesario saber actualmente. Destacan especialmente sus tablas, ya sea de factores de riesgo, de evaluación clínica o de diagnóstico diferencial, ya que facilitan enormemente la orientación del lector frente a diversos cuadros clínicos. También puede señalarse que las citas bibliográficas son relativamente pocas pero muy bien seleccionadas.

En resumen, es una muy buena revisión de la patología neurológica, llevada a cabo con experiencia clínica y amor por la enseñanza. Se recomienda su lectura a estudiantes y médicos no especialistas; pero el especialista también puede usarlo para una revisión rápida de cualquier tema.

Archibaldo Donoso S.

\section{Tratado de Neuropsicología}

Editores: Andrea Slachevsky, Patricio Fuentes y Facundo Manes. Editorial Akadia. Buenos Aires, 2008.

$\mathrm{N}$ uestra literatura científica se ha enriquecido con el nuevo libro de Neuropsicología, que es un magnífico esfuerzo editorial, donde los editoresson acompañados por una pléyada de especialista que desarrollan temas de su ámbito de competencia y hacen del libro un órgano obligado de consulta.

Dentro de la vocación científico-clínica de la neuropsicología se tocan todos los aspectos que hacen relación entre cerebro y cognición, entre bioquímica y comportamiento, entre semántica y lenguaje, entre lesiones isquémicas, degenerativas, genéticas o infecciosas y cambios cognitivos-conductuales, que tengan una expresión neuropsicológica mesurable.

El entorno latinoamericano está de plácemes ante un magnifico libro escrito en castellano. Es la ciencia escrita en nuestro idioma madre, que ha llegado a nosotros para facilitarnos la comprensión y establecer el necesario acercamiento entre libro y lector.

La Revista de Neuropsiquiatría se complace en presentar a nuestros socios, este nuevo libro de Neuropsicología. 